\title{
Hacia un enfoque integrador de la sostenibilidad: Explorando sinergias entre género y medio ambiente
}

\author{
Isabel Pla Julián y Sandra Guevara de Molina
}

Occidente atraviesa por una de sus peores crisis económicas, pero los gobiernos se ocupan del equilibrio macroeconómico sin abordar la desconexión entre economía y medio ambiente, ni los componentes sociales del desarrollo. La degradación ecológica planetaria y su impacto en el bienestar requieren un enfoque sostenible. Aunque ha habido avances desde la Conferencia de las Naciones Unidas sobre el Medio Ambiente y el Desarrollo de 1992, aún no se ha adoptado una vía de desarrollo que contemple el funcionamiento de los ecosistemas o las persistentes desigualdades sociales y de género. Las economistas feministas han elaborado propuestas teóricas y metodológicas tendientes a reconocer el valor del trabajo doméstico, que podrían fortalecerse mediante una perspectiva ecológica. Asimismo, el desarrollo sostenible podría incorporar la perspectiva de género y la ética del cuidado cuya conexión se examina aquí, explorándose las sinergias entre género y medio ambiente y delineando un enfoque integrador sobre la sostenibilidad.

PALABRAS CLAVE

CLASIFICACIÓN JEL

AUTORES
Crisis económica, desarrollo sostenible, aspectos económicos, aspectos sociales, incorporación de la perspectiva de género, mujeres, igualdad de género, ecología, feminismo

B54, Q01, Q57

Isabel Pla Julián es profesora titular del Departamento de Economía Aplicada, Facultad de Economía de la Universidad de Valencia (España).isabel.pla@uv.es

Sandra Guevara de Molina es candidata al doctorado, Universidad de Valencia (España). sanguede@alumni.uv.es 


\section{I}

\section{Introducción}

En los últimos años el mundo ha enfrentado la crisis económica más grave desde la Gran Depresión, y las perspectivas son sombrías. En respuesta a ella se ha tomado toda una serie de medidas económicas y financieras, centradas sobre todo en restablecer el equilibrio macroeconómico, reducir el déficit fiscal, evitar el colapso de las instituciones financieras y, más recientemente, recuperar el crecimiento, que se sigue considerando como la panacea para todos los grandes problemas económicos del mundo moderno (Daly, 2005), pese a que en estudios realizados últimamente en algunos países no se comprueba ninguna correlación importante entre el crecimiento y el desarrollo humano (PNUD, 2011).

La crisis ha supuesto un alto precio a nivel humano, al afectar el ingreso de los trabajadores, aumentar la vulnerabilidad de los marginados, limitar el acceso a la salud y la educación y exacerbar los conflictos. El grado de impacto de esos problemas se ve influenciado por factores tales como el género y la región geográfica de la que se trate. $\mathrm{Al}$ mismo tiempo, las catástrofes naturales, la desertificación y las pérdidas de diversidad biológica también están provocando estragos, especialmente entre los grupos vulnerables. Pese a que ya han transcurrido 20 años desde la Conferencia de las Naciones Unidas sobre el Medio Ambiente y el Desarrollo (CNUMAD), que puso de relieve el grave deterioro ecológico de nuestro planeta y sus consecuencias para el bienestar humano, seguimos enfrentando los mismos problemas, agravados por nuevos desafíos surgidos de la falta de una perspectiva global y de lo limitado de las medidas tomadas al respecto. Se han registrado algunos avances, pero el desarrollo sostenible dista mucho todavía de haberse alcanzado. La Conferencia de las Naciones Unidas sobre el Desarrollo Sostenible (Río+20) puso de manifiesto la gran relevancia del crecimiento (pero desde la perspectiva de una economía verde) y la necesidad de contar con mecanismos institucionales que promuevan la sostenibilidad.

En ese contexto cabe destacar que el desarrollo sostenible no se puede lograr sin reconocer los servicios que los ecosistemas nos brindan y las persistentes desigualdades que se registran en nuestras sociedades, como las relacionadas con el género, la raza y la sexualidad, entre otras. María Novo (2007, pág. 13) sostiene: "Nadie, tampoco las mujeres, podrá salir adelante si no es bajo el soporte de una naturaleza que no haya sido sacrificada a los puros intereses económicos. Nadie, ningún hombre, llegará a conocer la experiencia generalizada de la dignidad en un mundo desigual en el que el $70 \%$ de los pobres de la tierra pertenece al colectivo femenino". Para abordar apropiadamente las interconexiones entre las personas de distintas partes del mundo y entre el ser humano y los ecosistemas es necesario desmantelar dualismos tales como los de público-privado, femenino-masculino, razón-emoción o progreso-conservación (Plumwood, 2002). Dichos dualismos entrañan una concepción jerárquica (Bosch, Carrasco y Grau, 2003) que impregna al modelo económico en su conjunto y define los comportamientos sociales y las políticas públicas.

Esos desafíos han dado lugar a profundos debates y a una amplia base de investigación. Las ecofeministas han puesto de relieve la necesidad de impugnar la invisibilidad de las mujeres, que comparte muchas características con la invisibilidad de la naturaleza. Las economistas feministas han hecho valiosas contribuciones a los marcos teóricos y metodológicos a fin de hacer visible el valor del trabajo doméstico. Por su parte, los economistas ecológicos hacen hincapié en la necesidad de tener en cuenta los principios que rigen la naturaleza para poder alcanzar el desarrollo sostenible. Las relaciones de poder y los valores que subyacen al sistema socioecológico que nosotros, los seres humanos y la naturaleza, conformamos deben revisarse. Esas propuestas podrían enriquecerse incorporando ambas perspectivas y así alcanzar el enfoque holístico que debería caracterizar al desarrollo sostenible. En este documento se exploran las posibles sinergias entre la ecología y el feminismo, buscando matices que podrían derivar en un reforzamiento mutuo y, al mismo tiempo, apoyar políticas públicas adecuadas, actividades de difusión y defensa de derechos y acciones positivas que impulsen los urgentes cambios que se necesitan. Tras la reflexión sobre esos temas, se delinea una concepción integradora de la sostenibilidad en aras de una mejor comprensión de los desafíos que se enfrentan y de la necesidad de políticas sistémicas transversales.

Luego de la Introducción inicial, en la sección II se examina la posible transformación del modelo económico prevaleciente en el mundo occidental, bajo las perspectivas ecológica y feminista, con particular referencia al ecofeminismo y la economía feminista. En 
la sección III se identifican algunos espacios existentes para avanzar hacia una visión integradora que favorezca el desarrollo sostenible mediante un cambio de valores, del modelo de desarrollo y de las relaciones de poder, haciendo más visible el papel de la mujer y delineando posteriormente una visión integradora de la sostenibilidad. Finalmente, en la sección IV se señalan las conclusiones del estudio.

\section{II}

\section{Cómo cambiar el modelo económico prevaleciente: incorporación de diferentes perspectivas e identificación de los aspectos comunes}

El llamado a una transformación real del modelo económico prevaleciente no es algo nuevo, de hecho, ha sido proclamado tanto por los economistas ecológicos como por las economistas feministas, y asimismo por parte de otros grupos haciendo hincapié en la necesidad de examinar la raíz de nuestros problemas. Por ejemplo, las ecofeministas han hecho evidente la estrecha interrelación entre el ser humano y la naturaleza, la manera en que las desigualdades de género afectan al desarrollo en la estructura actual y la diversidad de los desafíos que enfrentan las mujeres de todo el mundo debido a su limitado acceso a los recursos económicos y a su relación con la naturaleza. Otros resaltan la necesidad de revisar la conceptualización misma de la ciencia económica y el desarrollo. A continuación se resumen las dos perspectivas que conforman el ecofeminismo.

\section{La perspectiva ecológica}

El tema ambiental es parte de la actual agenda internacional, así como de las nacionales. Es importante reconocer los significativos avances que se han registrado desde los años sesenta, cuando el ecologismo se convirtió en un movimiento trascendental que, en sus inicios, se preocupaba principalmente de la preservación de las especies, el control de la contaminación y la protección de los recursos naturales; así lo revelan sus principales corrientes. El libro de Rachel Carson, Primavera silenciosa, obra publicada en 1962, representó un hito que advertía acerca del terrible efecto de los productos agroquímicos sobre la salud humana (Nash, 1989). Además, la creciente frecuencia de las manifestaciones cívicas, los informes sobre la gravedad del daño ecológico generalizado (por ejemplo, Los límites del crecimiento, libro publicado por Meadows y otros en 1972) y las crisis petroleras de
1973 y 1979 ayudaron a sensibilizar al público acerca de la repercusión y amplitud del daño ecológico. Como consecuencia, a nivel nacional se promulgaron nuevas leyes para proteger las especies y prevenir y controlar la contaminación, en tanto que a nivel internacional se registraron acciones importantes. Ejemplo de ello son: el Programa sobre el Hombre y la Biosfera (1970) de la Organización de las Naciones Unidas para la Educación, la Ciencia y la Cultura (UNESCO), la Conferencia de las Naciones Unidas sobre el Medio Humano (1972), que estableció el Programa de las Naciones Unidas para el Medio Ambiente (PNUMA), y los primeros pasos para crear un marco jurídico internacional sobre las cuestiones ambientales (Vig y Axelrod, 1999).

Esas iniciativas partieron de un enfoque estructural sobre los problemas, recurriendo a modelos convencionales del desarrollo económico y tecnológico (Humphrey, 2001). Desde la óptica de la economía ambiental, la contaminación es una externalidad o consecuencia negativa que deriva de la ausencia de precio de mercado para el medio ambiente. Por ende, las soluciones a ese problema podrían incluir la aplicación de impuestos para internalizar el costo correspondiente, como propuso Pigou (1946), o la asignación de valor a los recursos naturales mediante el desarrollo de los derechos de propiedad (según lo sugerido por Coase) ${ }^{1}$. Posteriormente, han sido desarrolladas otras herramientas económicas para valorar la diversidad biológica, abordar el cambio climático y enfrentar distintos desafíos ambientales.

Conforme se fue aprendiendo más sobre el funcionamiento de los ecosistemas y profundizando en el conocimiento acerca del impacto que estos sufren

\footnotetext{
1 Mayores detalles sobre las diferencias entre esos dos enfoques véanse en Grossman (1999, págs. 538-568).
} 
como consecuencia de las actividades antropogénicas, fueron surgiendo enfoques más integrales que abarcan el funcionamiento del sistema económico en su conjunto y cuestionan el modelo prevaleciente, que socava la base material misma que le sirve de apoyo (Daly, 1996; Naredo, 2006). Esa ruptura ha permitido un inusual crecimiento económico que se desentiende totalmente de la capacidad de carga del planeta ${ }^{2}$. Ello ha sido posible gracias a las existencias relativamente abundantes de recursos naturales y debido a la idea de que la ciencia puede crear materiales sustitutos para todo, facilitando al mismo tiempo la adaptación a los cambios producidos en los ecosistemas como consecuencia de su explotación (Costanza, 2003). Por otra parte, se ha desvinculado al desarrollo económico de la desigualdad, la exclusión y la discriminación que ha provocado, por considerarse que esos problemas escapan al ámbito de la Economía (Naredo, 2006). Por lo tanto, los ecologistas preferirían un modelo económico más integral que tenga en cuenta los ecosistemas y su resiliencia ${ }^{3}$, en tanto que los proponentes de la economía ecológica, la ecología humana y la ecología política (entre otros) propugnan un enfoque más amplio que tome en consideración las interacciones entre el ser humano, la naturaleza y los aspectos distributivos.

En la Evaluación de los Ecosistemas del Milenio se pone de relieve el vínculo entre los ecosistemas, la actividad económica y el bienestar, así como entre la pobreza y el medio ambiente. Asimismo, se subraya que los ecosistemas no solo intervienen en la satisfacción de las necesidades básicas en cuanto a alimentos, medicamentos, energía, salud, seguridad, y otros, sino que además nos brindan servicios que comprenden la purificación del aire y el agua, las condiciones climáticas y los espacios para finalidades culturales, espirituales, recreativas y educativas. En dicha evaluación se llamó la atención sobre el hecho de que nuestras crecientes demandas han provocado cambios sin precedentes en los ecosistemas en los últimos 50 años, que incluyen una pérdida considerable - y mayormente irreversible — de la diversidad biológica del planeta y cambios en las condiciones climáticas, todo lo cual merma la capacidad de la naturaleza de ofrecer sus servicios fundamentales

\footnotetext{
2 La "capacidad de carga" se refiere a la disponibilidad de recursos para satisfacer las necesidades de una especie a fin de que esta pueda sobrevivir, crecer y reproducirse, sin ningún efecto negativo en la estabilidad del sistema y su resiliencia.

3 La "resiliencia" en la ecología se refiere a la capacidad de los ecosistemas de absorber trastornos y reorganizarse conforme cambian a fin de mantener, básicamente, la misma función, estructura e identidad y los mismos elementos de retroalimentación (Walker y otros, 2004).
}

a la humanidad. Esa situación deja en condiciones vulnerables a la población mundial, especialmente a los aproximadamente 2.000 millones de personas (DAES, 2009) que viven en regiones secas y se ven más expuestas a sufrir privaciones, enfermedades y el incremento de sus probabilidades de caer en la pobreza. Esa situación exacerba las desigualdades y disparidades entre grupos de personas y provoca conflictos sociales (PNUMA, 2005). Pese a ciertos avances recientes, el $22 \%$ de la población total de América Latina y el Caribe carece de acceso a agua de grifo y el $45 \%$ de la población rural carece de servicios de saneamiento, factores que tienen un impacto directo en las tasas de salud y de mortalidad. Se estima que entre 35 millones y 40 millones de personas no tienen acceso a servicios de energía básicos (electricidad y combustibles), y alrededor de 35.000 personas mueren anualmente por causas relacionadas con la contaminación atmosférica; en tanto que el cambio climático, la pobreza y la pérdida de diversidad biológica están incrementando la vulnerabilidad ante los desastres naturales, que ya ha tenido una grave repercusión en la economía y la población de la región (CEPAL, 2012).

Cabe señalar que esos problemas no solo afectan a quienes sufren directamente privaciones o catástrofes naturales. En la lucha por superar esas situaciones, las alternativas a disposición de los afectados podrían representar una amenaza para otros y provocar así conflictos sociales, inseguridad, guerras o corrientes migratorias hacia países más ricos en recursos, más pacíficos o más estables. De igual manera, una actividad económica en una zona determinada podría afectar no solo al medio ambiente inmediato, sino también al de una región o un país vecino, y provocar con ello tensiones internacionales. En resumen, el ser humano y la naturaleza no son independientes entre sí, sino que - por el contrario- conforman un sistema socioecológico que debe gestionarse como un todo (Young y otros, 2006; Bono, 2008a). Una mayor comprensión sobre ese hecho ha promovido visiones más integradoras, como la ecología política, la ecología social, la ecología humana o la ecología profunda.

Considerando que en un mundo en que prevalezcan la pobreza y la desigualdad siempre será proclive a las crisis sociales, ecológicas y de otra índole, los autores del Informe de la Comisión Mundial sobre el Medio Ambiente y el Desarrollo, titulado "Nuestro futuro común" (conocido también como "Informe Brundtland", 1987) sugirieron buscar una forma de desarrollo "que satisfaga las necesidades del presente sin comprometer la capacidad de las futuras generaciones para satisfacer las propias" (Asamblea General de las Naciones Unidas, 
1987). Eso no significa que todas las generaciones deban dejar el mundo tal como lo encontraron: lo que se debe preservar son las oportunidades para que las generaciones futuras puedan tener libertades esenciales, tomar decisiones y disfrutar de la vida (Bono, 2008a). El concepto de desarrollo sostenible propone integrar la ecología, la economía y la sociedad, y constituyó el punto central de la Conferencia de las Naciones Unidas sobre el Medio Ambiente y el Desarrollo (CNUMAD) o Cumbre de Río, celebrada en 1992.

Sin embargo, el concepto de "desarrollo sostenible" se ha considerado un oxímoron (Naredo, 2006; Redclift, 2009) en razón de que no cuestiona el crecimiento económico en sí mismo, sino únicamente su sostenibilidad desde el punto de vista social y ambiental. Pero es preciso tener en cuenta que para que un concepto de desarrollo reciba el apoyo general en una reunión multilateral debe satisfacer las necesidades de países que tienen realidades diferentes. En ese sentido, no se le puede negar a un país empobrecido el derecho a hacer crecer su economía o buscar un nivel de vida mejor, aun cuando la forma como se logre es importante y el crecimiento en sí mismo no conduzca necesariamente a mejores niveles de vida para la población. Por lo tanto, es crucial tomar en consideración los factores sociales, ambientales, tecnológicos y culturales, entre otros. La situación de los países desarrollados es distinta: en su caso, las pautas de producción y consumo son el tema clave, en tanto que la búsqueda de un crecimiento sin límites podría cuestionarse.

Ese debate resulta especialmente pertinente en la actualidad, cuando los términos "desarrollo sostenible" o "sostenibilidad" figuran en la mayoría de las agendas nacionales e internacionales. Desde la adopción del Programa 21 de la CNUMAD en 1992, la mayoría de los países y muchas ciudades han estado trabajando en torno de sus correspondientes planes de acción de desarrollo sostenible, haciendo hincapié en abordar simultáneamente las cuestiones ambientales, económicas y sociales. Sin embargo, en muchos casos la expresión "desarrollo sostenible" se utiliza con fines de mercadeo o publicitarios, con o sin base sólida. El movimiento ecológico ofrece varios puntos de vista alternativos sobre las limitaciones de la naturaleza en tanto sistema, que se pueden considerar de manera determinista, adaptativa o innovadora en función de si el medio ambiente natural se estima fundamental, reemplazable o no siempre reemplazable, respectivamente (Costanza, 1994). En la búsqueda de un desarrollo humano ambientalmente sostenible, la tecnología ha de desempeñar una función clave desacoplando el crecimiento, por una parte, de la contaminación y la degradación ambiental, por otra (Almenar, 2008). Ciertamente, la tecnología y el conocimiento influyen en el carácter del producto (Schmid, 1987), pero las instituciones tienen la posibilidad de promover avances tecnológicos con fundamento ecológico, suministrando un marco para las transformaciones que requiere el desarrollo (North, 1990).

Todos esos aspectos se reúnen en una ulterior noción integral de desarrollo sostenible que va más allá de las interacciones entre el medio ambiente, la economía y la sociedad, y postula el desarrollo sostenible como una transformación global de la sociedad, no solo en cuanto a metas sino también en cuanto a medios. Por ende, además de satisfacer las necesidades humanas y respetar al mismo tiempo la capacidad de sustento del planeta, esa nueva visión incorpora la tecnología y las instituciones como dos pilares fundamentales adicionales (Tomás Carpi, 2007 y 2008). Ese concepto se nutre de valores esenciales como los de ecoeficiencia, solidaridad y activismo social, que lo convierten en un buen punto de partida para explorar las sinergias con las propuestas feministas en la búsqueda de una concepción integral de la sostenibilidad.

En el documento emanado de la Cumbre Río+20 ("El futuro que queremos"), además de promoverse una economía verde en el contexto del desarrollo sostenible, se promueve un compromiso político llamado a revigorizar la alianza mundial para el desarrollo sostenible, así como a mejorar la capacidad y coherencia, integrando la sostenibilidad en todos los niveles de toma de decisiones, ya sea en el ámbito público como en el privado (Conferencia de las Naciones Unidas sobre el Desarrollo Sostenible, 2012).

\section{La perspectiva feminista}

Al igual que el ecologismo, el feminismo abarca diversos enfoques, cada uno de ellos influenciado por las experiencias particulares de las mujeres de distintas partes del mundo. Al principio, las exigencias feministas se relacionaban principalmente con el derecho a la educación (Rivera, 1991) y, posteriormente, con el derecho a voto (Freedman, 2004; Rivera, 1991). El segundo sexo, publicado por Simone de Beauvoir en 1949, se considera la piedra angular de las nuevas reivindicaciones feministas (Freedman, 2004; Sánchez, 2001). En opinión de Valcárcel (2008), ese libro dio lugar a muchas explicaciones teóricas sobre la subordinación de la mujer. Asimismo, influenció los movimientos de preconización de la causa en todo el mundo que redundaron en un aumento gradual de la participación 
de la mujer a los niveles institucional y público, y en la introducción de políticas activas para fomentar su mayor involucramiento a partir de entonces.

Otra gran fuente de diversidad se encuentra en los llamados feminismos negros - referidos a posturas afroestadounidenses - y en las opiniones de las feministas de los países en desarrollo (Freedman, 2004; Mies y Shiva, 1997). Sus argumentaciones acerca de la multiplicidad de identidades y la interacción de distintos factores en la determinación de las desigualdades (tales como raza, grupo étnico o casta, cultura, religión, nivel económico y sexo, entre otros) enriquecieron la perspectiva feminista, pero al mismo tiempo introdujeron algunas discrepancias. No obstante, a pesar de sus diferencias, todas esas ideologías comparten el objetivo común de poner fin a la opresión de ese sujeto moralmente valioso que es la mujer (Howie y Tauchert, 2002).

Fue precisamente en el contexto del feminismo negro que tomó forma el concepto de "ecofeminismo", término que se atribuye a la escritora francesa Françoise d'Eaubonne (Mellor, 1997) y en el que se combina una visión de la humanidad desde la perspectiva de género (violeta), por una parte, con el ecologismo (verde), por otra. El concepto representa un desafío y, al mismo tiempo, una importante contribución a ambos: feminismo y ecologismo (Plumwood, 1993; Moore, 2004). En vista de la pluralidad que caracteriza a estos movimientos, su convergencia ha dado lugar a una amplia gama de enfoques ecofeministas o ecofeminismos, que abarcan desde el activismo hasta contribuciones políticas y teóricas que son valiosas para el desarrollo sostenible. Tales enfoques varían según la percepción de la conexión entre la mujer y la naturaleza (en función de la rama particular de feminismo de la que provengan o de la profundidad del tratamiento de la temática ambiental), como también según el ámbito de preocupación o contexto específico del que provienen esas reflexiones, sobre todo por las condiciones históricas y materiales de las vidas de las mujeres (Mellor, 1997; Kao, 2010). Esa diversidad se puede apreciar fácilmente pasando revista a algunos de los argumentos propuestos por las ecofeministas. En su libro El feminismo o la muerte, D'Eaubonne (1974) atribuyó la responsabilidad de la degradación ambiental al sistema patriarcal, que explota la naturaleza al tiempo que somete a la mujer (Agra Romero, 1998). Esa opinión es compartida por King, para quien la devastación de la Tierra muestra la misma mentalidad masculina que busca denegar a la mujer el derecho a controlar su propio cuerpo y su propia sexualidad por medio de distintos mecanismos de control personal y estatal (Merchant, 1995; Agra Romero, 1998).
El movimiento Chipko 4 iniciado por un grupo de mujeres que procuran detener la deforestación en el norte de la India, se preocupa de preservar la fuente de bienestar de su comunidad haciendo un llamado para optar por una economía de subsistencia (Mellor, 1997; Merchant 1995; Mies y Shiva, 1997). De igual manera, el Movimiento Cinturón Verde ${ }^{5}$ en Kenya, fundado en 1977 por Wangari Maathai, Premio Nóbel de la Paz, comenzó por enfrentar la creciente deforestación, erosión del suelo y escasez de agua plantando árboles (Merchant, 1995), y posteriormente evolucionó para convertirse en un movimiento de promoción de los derechos humanos y la gestión sostenible de los recursos, así como de apoyo a la buena gobernanza, los principios democráticos y la paz. Una de las pioneras ecofeministas de América Latina fue la bióloga y arquitecta ítalo-venezolana Giovanna Merola, cuya visión aspiraba a integrar a los seres humanos en su entorno natural y urbano con un enfoque feminista (Salleh, 1997).

Se han propuesto distintas clasificaciones del ecofeminismo (véanse Agra Romero, 1998; Merchant, 1995; Mellor, 1997; o Puleo, 2002 y 2007, entre otros autores) y, si bien catalogar puede resultar difícil e incluso a veces limitativo o controvertido, se considera que sería útil analizar algunas de esas categorías en este documento en la búsqueda de contribuciones útiles a su objetivo. Las esencialistas o ecofeministas clásicas sostienen que la mujer está mejor preparada que el hombre para solucionar las crisis ecológicas pues es intrínsecamente dispensadora de cuidados y protectora, a diferencia del hombre, que es esencialmente competitivo y destructor (Puleo, 2002). Las ecofeministas de la afinidad parten de una óptica más inclusiva y consideran que la conexión mujer-naturaleza no está asentada en la biología, sino que se deriva de la cultura y las tradiciones (Mellor, 1997). El enfoque constructivista es similar pues considera a esa conexión como un elemento sociohistórico usado para ejercer un control patriarcal. Ese punto de vista privilegia lo político sobre lo personal (en relación con este enfoque, véanse Biehl, 1991; o Heller, 1999).

Se tiende a asociar el ecofeminismo con su vertiente espiritual, es decir, la que asume la conexión mujernaturaleza como un vínculo metafísico u ontológico, si bien hay grandes diferencias entre las apreciaciones

\footnotetext{
${ }^{4}$ Nombre con que se conoce a un movimiento ecológico formado, fundamentalmente, por campesinos y pequeños artesanos empobrecidos de la India, donde la participación social de las mujeres es especialmente notable y cuya filosofía se basa en la concepción del sarvodaya gandhiano y de las técnicas del uso de la resistencia no violenta.

${ }^{5}$ Proyecto de plantación de árboles en África para promover la biodiversidad y al mismo tiempo crear empleos para las mujeres.
} 
que allí se incluyen y en el involucramiento político. Una exponente fundamental del ecofeminismo, Vandana Shiva (ganadora en 1993 del Premio Right Livelihood, conocido como "Premio Nóbel Alternativo") señala que el desarrollo técnico de Occidente es fuente de violencia contra la mujer y la naturaleza, y apuesta por un modelo ambientalmente sostenible basado en la concepción ontológica de lo femenino como principio transgenérico y en la continuidad indisoluble entre sociedad y naturaleza. La mujer y la naturaleza son indiscutiblemente creadoras de vida y productividad fuera del marco de los procesos de acumulación de capital (Mies y Shiva, 1997). Ivone Gebara, una de las principales voces del pensamiento ecofeminista teológico en América Latina, equipara la justicia social con la justicia ecológica (Puleo, 2002 y 2007; Kao, 2010). Sin embargo, en la región existen (al igual que en otras partes del mundo) otros enfoques espirituales, influenciados por las cosmogonías indígenas y por las experiencias diarias de las mujeres (Ress, 2003).

La economista india Bina Agarwal propone un ambientalismo feminista, al considerar que la conexión mujer-naturaleza está enraizada en la economía familiar, donde se asignan responsabilidades de género. La doctora Agarwal observa que las experiencias a nivel de la familia pueden ofrecer excelentes ejemplos para la toma de medidas de protección ambiental a mayor escala. En su opinión, la conexión entre el desarrollo, la redistribución y la ecología requiere de una perspectiva transformadora, pues la aspiración al control tecnológico subvalora a la mujer, la naturaleza y los sentimientos (Agarwal, 1992). Por su parte, Alicia Puleo (2008) propone un ecofeminismo ilustrado, concebido como proyecto ético y político que propugna la igualdad y la autonomía de las mujeres, independientemente de su proveniencia social, cultural o étnica. Ese enfoque acepta, con cautela, los beneficios de la ciencia y la tecnología y promueve la universalización de valores tales como la ética del cuidado de los seres humanos y la naturaleza, afirmando la unidad y la continuidad entre ellos (desde el punto de vista evolucionista), así como la compasión.

Entretanto, la distribución de los recursos naturales y el acceso a ellos constituyen un componente clave de la ecología política feminista. La variable crítica según ese enfoque es la manera en que la clase social, la casta, la raza y la cultura interactúan con el género. Para sus exponentes hay tres elementos fundamentales, a saber: i) conocimiento basado en el género, es decir, la sabiduría de supervivencia desarrollada por las mujeres para mantener y proteger un ambiente saludable en su hogar, así como en sus lugares de trabajo y sus comunidades; ii) los derechos y responsabilidades ambientales según el género, que implican un acceso diferente a la propiedad, los recursos, el espacio público, los derechos jurídicos y el derecho común, y iii) las organizaciones basadas en el género, es decir, el activismo político-ambiental en el que las mujeres participan cada vez más, redefiniendo con ello su identidad, el significado del género y el tipo de problemas ambientales enfrentados (Rocheleau, Thomas-Slayter y Wangari, 1996).

Un aspecto que todas esas vertientes del ecofeminismo comparten es el de la "invisibilidad" de la mujer y la naturaleza debido a su desvalorización por los sistemas de conocimiento científico y el poder económico dominados por los hombres (Stoddart y Tindall, 2011). Según Novo (2007), ello obedece a que la mujer no produce plusvalía. Para esa autora, es menester reevaluar la "huella civilizatoria", es decir, la energía invertida en tiempo, afecto, amor o cuidado que las personas necesitan para atender a sus necesidades reales, y también la "huella ecológica" dejada en el planeta por las exigencias de nuestro estilo de vida. Shiva y Novo sostienen que cuando los ciclos de vida funcionan bien y se mantienen vigentes se vuelven invisibles a los ojos, razón por la que no se les asigna valor alguno, a menos que se produzca una interrupción en su funcionamiento. Plumwood (1993) usa el término backgrounding (es decir, opacamiento o colocación en un segundo plano) para describir una de las maneras en que tanto la mujer como la naturaleza se han visto desvalorizadas.

Para las economistas feministas, considerar que solo el trabajo remunerado es "productivo" vuelve invisibles, desde el punto de vista económico, el trabajo reproductivo y doméstico, desempeñado mayormente por la mujer (Durán, 2001 y 2012). Por ende, las políticas y los programas socioeconómicos diseñados desde esa óptica son ineficaces para corregir las inequidades de género (Carrasco y Mayordomo, 2000). Además, al no asignarse un valor económico a ese tipo de trabajo se cae en una subestimación general de la contribución de la mujer al desarrollo, especialmente en relación con elementos intangibles como el apoyo emocional, el infundir ánimo, el estímulo de aptitudes, las relaciones de familia y la crianza (Bosch, Carrasco y Grau, 2003). Esa inequidad no está limitada a la privacidad del hogar o al entorno de trabajo, sino que impregna todos los ámbitos de la vida: desde los medios académicos hasta las empresas, así como también las instituciones representativas sociales y políticas de casi todas las sociedades.

La filósofa australiana Val Plumwood (2002) recalcó la necesidad de trascender los dualismos jerárquicos naturaleza-cultura, mujer-hombre, cuerpo- 
mente, materia-espíritu y afecto-racionalidad, los que constituyen la base de la degradación de la naturaleza y reflejan una filosofía occidental arrogante que tiene por núcleo a un "yo" masculino dominante, separado de su propio cuerpo y sus propios sentimientos, de la mujer y del resto de la humanidad, así como de la Tierra que lo sustenta. Ello ha propiciado llamados en favor de un marco conceptual que tenga en cuenta la interrelación entre la subyugación de la mujer y la naturaleza, y una reconceptualización del feminismo y la ética ambiental que se oponga a la lógica de la dominación y reconozca al mismo tiempo valores como el cuidado, el amor y la amistad (Warren, 2009). Salleh (1997) propugna un nuevo contrato justo y humano con la naturaleza, argumentando que la opresión de los hombres sobre otros hombres, las mujeres y la naturaleza solamente se podrá desmantelar transformando el modelo económico.

Pese a los logros registrados por el feminismo en los últimos dos siglos, aún subsisten inequidades significativas e insostenibles. Eso explica la aspiración a que se produzcan cambios sustanciales y la necesidad de contar con políticas de desarrollo. En este trabajo se considera que la consolidación de un enfoque más coherente e integral, que combine el género y la sostenibilidad, se traduciría en una mayor repercusión en el desarrollo.

\section{III}

\section{Espacios para una sinergia: hacia una visión integradora en cuanto al desarrollo sostenible}

La complejidad de los problemas abordados por las feministas, las ecofeministas y los ecologistas de todas las variantes es innegable, y pese a los elementos que tienen en común también existen desacuerdos ${ }^{6}$. Por ejemplo, si bien una de las grandes preocupaciones de los ecologistas es el antropocentrismo, las feministas acusan a los ambientalistas de no cuestionar el sistema patriarcal y basarse en los mecanismos y las estructuras de control prevalecientes (Bosch, Carrasco y Grau, 2003). En lugar de agregar argumentos al debate, en el presente artículo se prefiere explorar los ámbitos en que esos movimientos coinciden y tratar de aproximar sus propuestas. En primer lugar, porque las posiciones no son homogéneas en ninguno de los dos campos y, de cualquier manera, tienden a evolucionar. En segundo lugar, porque las inequidades de género, las tensiones sociales, los costos económicos y financieros y la pobreza que afligen a miles de millones de personas en todo el mundo, así como lo acelerado de las pérdidas de diversidad biológica, del cambio climático y de la desertificación, entre otros graves problemas ambientales

\footnotetext{
${ }^{6}$ En relación con este debate se han publicado muchos artículos: Zimmerman (1987); Warren y Cheney (1991); Plumwood (1993); Sessions (1991); y Bosch, Carrasco y Grau (2003) se cuentan entre los autores que han analizado minuciosamente las coincidencias y discrepancias entre el feminismo y el ecologismo.
}

que afectan al bienestar humano, hacen necesario un enfoque integrador y multidisciplinario en que se incorporen los distintos aspectos de la realidad (Bono, 2008b; Young y otros, 2006).

\section{La invisibilidad de la mujer y la naturaleza}

Como ya se señaló, hace mucho tiempo que la sociedad en general y los economistas en particular subestiman el trabajo doméstico y reproductivo, hecho que lo ha vuelto invisible, pese a que los hogares son como talleres de servicio y ningún otro sector productivo se les equipara en cuanto al volumen o la relevancia económica de su producto (Durán, 2012). De igual manera, no se asigna ningún valor a los servicios y recursos proporcionados por la naturaleza, haciendo caso omiso de su contribución esencial al bienestar humano, así como de las consecuencias que genera su perturbación, lo que conduce en última instancia al uso irracional y la degradación de los ecosistemas y la interrupción de los ciclos biogeoquímicos. La ausencia de un precio de mercado parece denotar una falta de importancia y entraña invisibilidad (Novo, 2007). Por ello, hay quienes sostienen que si se asignara un valor económico a los recursos naturales y a las externalidades negativas que afectan a la naturaleza se promovería una gestión ambiental sensata (Kriström, 1995, citado por Salvador del Saz, 2008). 
Los sistemas de valoración, los indicadores de sostenibilidad, las propuestas de reforma tributaria, los sistemas de gestión ambiental y las evaluaciones de impacto ambiental, los marcos jurídicos para penalizar o prevenir una ulterior contaminación y degradación ambiental son todas sugerencias valiosas que ayudan a superar la invisibilidad de la naturaleza. No obstante, la valoración de estos ámbitos podría ser inconmensurable (Martínez-Alier, 2007), en cuyo caso podría ser más adecuado un enfoque holístico que refleje la manera en que funcionan los ecosistemas.

De igual manera, visibilizar la cantidad total de trabajo que llevan a cabo las mujeres es una tarea compleja, pues entraña una concepción multidimensional (en tiempo y espacio) enmarcada por instituciones formales e informales que son difíciles de cambiar, todo lo cual representa un desafío de largo alcance. El cuidado tiene muchos aspectos físicos, incluidas las funciones de curación y de limpieza, conlleva vigilancia (para evitar incidentes o enfermedades), pero también entraña componentes de gestión, representación de la familia y comunicación. Se trata de elementos difíciles de separar conceptualmente y, más aún, de cuantificar en tiempo y valor (Durán, 2011).

Hay varias propuestas, vinculadas al mandato emanado de la Declaración y la Plataforma de Acción de Beijing, que procuran modificar el marco conceptual o mejorar las herramientas estadísticas para visibilizar el trabajo no remunerado. Picchio (2005) sugiere reformular el ciclo de producción y distribución del mercado, en tanto que Durán (2001) propone mejorar las cuentas nacionales usando cuentas satélites de los hogares que atribuyan un valor monetario al trabajo doméstico y la prestación de cuidados. La Oficina de Estadísticas de las Comunidades Europeas (EUROSTAT) y la Comisión Económica para América Latina y el Caribe (CEPAL) han realizado encuestas sobre el uso del tiempo, que por el momento se considera que constituyen la mejor herramienta disponible (Durán, 2012). Carrasco y Mayordomo (2000) propusieron una encuesta no androcéntrica de la población activa y Carrasco y Serrano (2011) crearon una nueva metodología que consiste en recabar información tanto acerca de las actividades del hogar como sobre las actividades de mercado, superando así algunas de las limitaciones de las bases de datos usadas actualmente para calcular las cuentas satélites de los hogares. En América Latina se han registrado grandes avances en ese ámbito usando distintas metodologías, particularmente módulos especiales en encuestas regulares a los hogares (Durán y Milosavljevic, 2012). Todas esas herramientas han sido de gran ayuda para demostrar el alcance de las desigualdades de género prevalecientes y el de subordinación de la mujer, lo que representa un desafío para las políticas públicas (Rodríguez Enríquez, 2012).

Picchio propone una reformulación del ciclo de producción y distribución del mercado, replanteando no solo las condiciones de la producción de mercado, sino también las condiciones de reproducción de la fuerza laboral. La autora recalca que gracias a las actividades domésticas y la prestación de cuidados que tienen lugar en la esfera de la familia, los miembros de esta que tienen un trabajo remunerado fuera de su hogar pueden seguir desempeñándolo. Asimismo, establece una distinción entre tres funciones económicas fundamentales para el desarrollo humano a nivel del hogar: en primer lugar, la extensión del ingreso monetario o salario real a través de la provisión de bienes, alimentos, ropa limpia, y otros; en segundo lugar, la expansión del bienestar con el fomento de las capacidades humanas y el funcionamiento efectivo en la esfera social; y, en tercer lugar, el apoyo brindado por la unidad familiar a los procesos selectivos que tienen lugar en la economía de mercado, en cuanto a las aptitudes usadas en el proceso de producción de bienes y servicios. Picchio (2001 y 2005) define así un espacio económico dedicado al desarrollo humano, conformado por actividades cuya finalidad directa es el bienestar de las personas y no la valoración de bienes (véase el gráfico 1).

En el modelo se abordan aspectos clave de la invisibilidad y se resalta la interacción constante entre trabajo remunerado y trabajo no remunerado, la dificultad de asignar un valor monetario al trabajo doméstico (Durán, 2012) y su capacidad para transformar los niveles de vida en bienestar (Rodríguez Enríquez, 2012). No obstante, se replica la desconexión economía-naturaleza del modelo económico prevaleciente, reforzando indirectamente la invisibilidad de la naturaleza. Para integrar la perspectiva ecológica se debería reformular todo el ciclo con respecto a la naturaleza, para lo cual sería necesario reconocer que la producción y distribución de mercado, así como todas las actividades del espacio de desarrollo humano, dependen de los recursos y servicios proporcionados por los ecosistemas (ciclos biogeoquímicos, espacios, información), y que esas actividades generan contaminación, desechos, y provocan una degradación de la diversidad biológica que, tarde o temprano, incidirá en el bienestar humano. Esos intercambios con la naturaleza (insumos y productos) deberían tenerse en cuenta, junto con la capacidad de resiliencia de esta, a fin de asegurar la sostenibilidad. De ese modo, ambas invisibilidades se abordarían al mismo tiempo. 


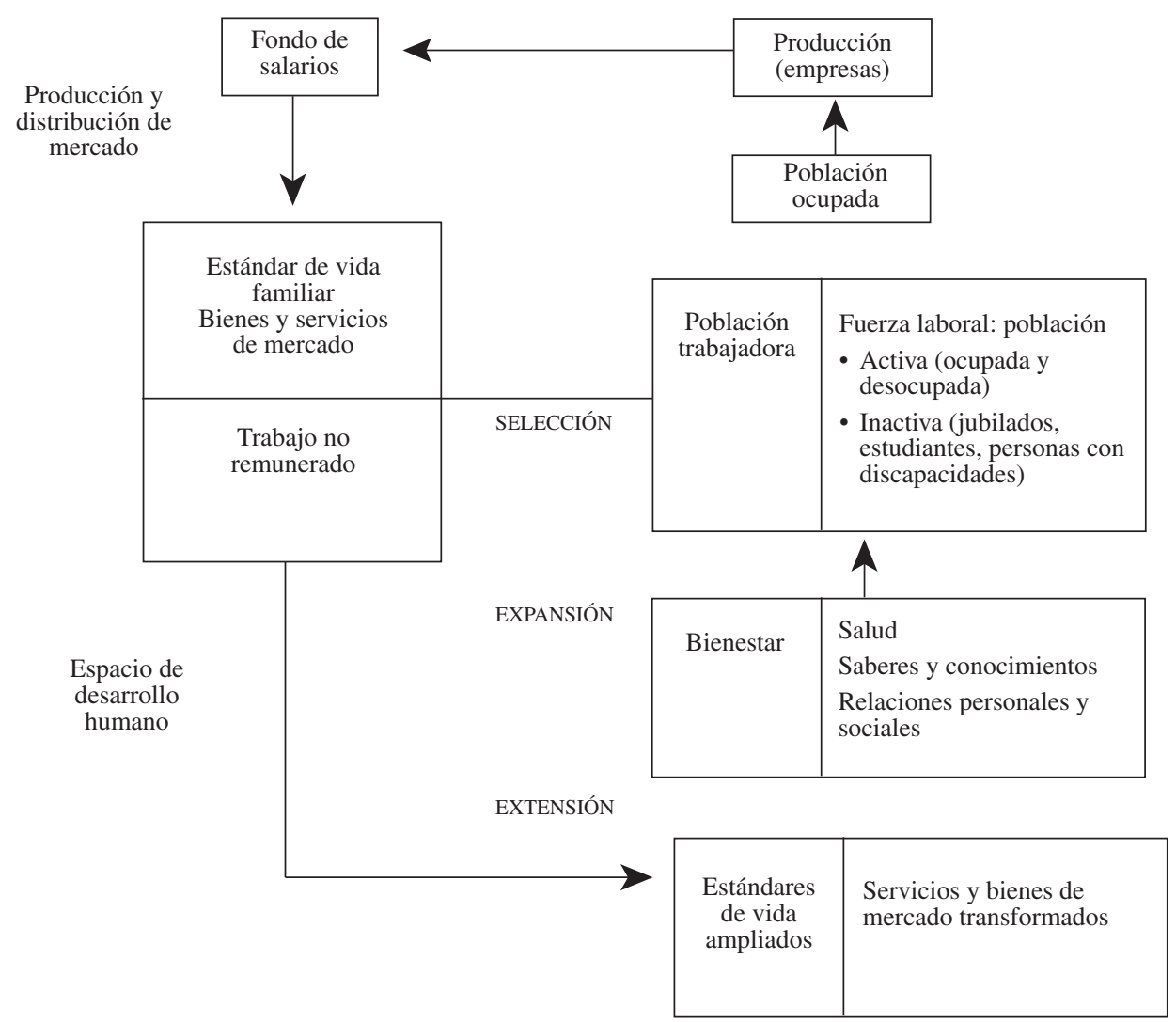

Fuente: Antonella Picchio, "La economía política y la investigación sobre las condiciones de vida", Por una economía sobre la vida, Gemma Cairó i Céspedes y Maribel Mayordomo (comps.), Barcelona, Icaria-Más Madera, 2005.

La introducción de una dimensión temporal en ese modelo ampliaría aún más su alcance. La naturaleza necesita tiempo para recuperarse de ciertos impactos, en lo que se asemeja a la capacidad de resiliencia humana. El derecho de las generaciones futuras a satisfacer sus necesidades se vincula no solo con el uso de los bienes y servicios proporcionados por la naturaleza, sino también con la realización de las actividades reproductivas y el suministro de cuidados y apoyo, tareas estas que tradicionalmente han estado a cargo de la mujer. Durán (2011) hace referencia a un contrato social intergeneracional implícito, es decir, un intercambio diferido en el que los cuidados y servicios recibidos se devuelven a sus proveedores a mediano o largo plazo, o se traspasan a la generación siguiente. Además, es preciso insistir en la necesidad de que tanto mujeres como hombres, compartan responsabilidades en la esfera doméstica. En la historia reciente, ante la ausencia de corresponsabilidad doméstica, se ha generado un cambio significativo debido a las transferencias que han tenido lugar entre mujeres de distintas partes del mundo. De hecho, la demanda globalizada de trabajadoras domésticas constituye una de las principales razones de la feminización de las migraciones y del surgimiento de la "cadena global de cuidados" (Durán, 2012; Hochschild, 2004; Pla, 2009). Igualmente, la solidaridad con los marginados es una consideración clave para la sostenibilidad, y aún es necesario seguir explorando las maneras de incluir ese elemento en el modelo.

\section{Un cambio de valores}

Para poder abordar adecuadamente las disparidades de género y los desafíos ambientales es necesario cambiar el modo en que se asigna valor a la mujer y a la naturaleza, pues dicho valor determina el comportamiento social hacia ellas. Ciertamente es importante visibilizar las actividades tangibles e intangibles que se realizan en el hogar y que facilitan el funcionamiento ordenado de todo el sistema económico, pero también hay que dejar de 
considerar esas actividades como un deber o una obligación de género que por añadidura se puede reemplazar con un trabajo no especializado en condiciones precarias (Pla, 2008). La distribución de las labores domésticas es parte de la división sexual del trabajo determinada por las pautas culturales y la racionalidad económica (Rodríguez Enríquez, 2012). Para poder desmantelar la cultura patriarcal que subyace a las desigualdades de género se necesita un nuevo contenido simbólico en la memoria colectiva (Montaño, 2010). De igual modo, para poder reevaluar la relevancia de los ecosistemas para el bienestar humano y el efecto que las actividades antropogénicas tienen en ellos (Costanza, 2003; Nash, 1989) no basta con realizar evaluaciones de impacto ambiental, asignar valores económicos a los recursos o tratar de usarlos de manera más eficiente, sino que se debe redefinir nuestro actual estilo de vida, que se caracteriza por un consumismo desproporcionado y supone una carga excesiva sobre el planeta. Esa carga compromete la capacidad de autorregulación de los ecosistemas y la disponibilidad de recursos y servicios, ahora y en el futuro. Se han formulado distintas propuestas para abordar ese desafío, y hace tiempo que en el ámbito de la Comisión sobre el Desarrollo Sostenible de las Naciones Unidas se registran deliberaciones acerca de los patrones de consumo y producción, sin que todavía se hayan realizado avances significativos.

Para provocar un cambio en el comportamiento social se debería poner más énfasis en la educación para la sostenibilidad, a fin de aumentar la sensibilidad pública y fomentar la adopción de esos nuevos valores. Es esencial comprender que no necesitamos "tener más" sino "estar mejor". La UNESCO ha participado activamente en la promoción de acciones para el Decenio de las Naciones Unidas de la Educación para el Desarrollo Sostenible, 2005-2014 (Resolución 57/254 de la Asamblea General de las Naciones Unidas, 2003). Como se indica en la Declaración de Bonn de 2009, la educación para el desarrollo sostenible debería "fomentar activamente la igualdad entre hombres y mujeres, así como también crear las condiciones y estrategias que permitan a las mujeres compartir conocimientos y experiencias conducentes al cambio social y el bienestar humano" (UNESCO, 2009). Ello ha dado lugar a iniciativas importantes en todo el mundo con respecto a la incorporación de la igualdad de género en todos los ámbitos comprendidos en el plan de aplicación de la unESCO, incluidas la elaboración de directrices y herramientas para la sensibilización acerca del género como parte de la orientación impartida a los docentes en el marco del Decenio de la Educación para el Desarrollo Sostenible. Otro gran avance lo constituye la Iniciativa de la Carta de la Tierra, mediante la cual organizaciones de la sociedad civil en todo el mundo han estado promoviendo la transición a un estilo de vida más sostenible (Bosselmann, 2004).

Esas iniciativas deberían secundarse con un apoyo institucional adecuado a los niveles nacional y local, como señal de un cambio en la prioridad asignada a las cuestiones ambientales y de género en las políticas públicas. Esas cuestiones deberían verse reflejadas en todos los reglamentos y políticas socioeconómicos, asî como en los programas de educación formal (primaria, secundaria y terciaria) a objeto de integrar esos temas en los planes de estudio existentes, sobre todo en los cursos de economía y negocios, en lugar de presentarlos como temas separados y desvinculados del resto del programa de estudio. En cuanto a la educación informal y el aumento de la conciencia pública, es fundamental establecer alianzas con los medios de difusión. Se debería alentar a las emisoras de radio y televisión a incorporar en su programación temas relacionados con la ética ecológica y de género en las horas de mayor sintonía, reemplazando la visión patriarcal, materialista y corta de miras que actualmente se promueve en la mayoría de los programas transmitidos. La utilización de antiestereotipos de género, es decir, la presentación de determinados valores positivos como estereotipos femeninos hasta que se acepten sin cuestionamientos (Jolly, 2004), ha sido una herramienta poderosa para el cambio. La UNESCO ha elaborado un conjunto de indicadores específicos sobre género, en que se aborda la intersección del empoderamiento de la mujer y el desarrollo de los medios de difusión, y ha impartido capacitación a periodistas a fin de mejorar sus actividades de difusión de noticias sobre temas relacionados directa o indirectamente con la mujer.

Otro aspecto que merece ser revalorado es la contribución de las mujeres del ámbito rural a la conservación de la naturaleza, como se mencionó anteriormente. Esa contribución no se ve motivada por opiniones esencialistas o por el deseo de regresar a prácticas precapitalistas, sino por la experiencia acumulada de dichas mujeres, cuya estrecha relación con el medio ambiente es valiosa para preservar los ecosistemas. Ellas han aprendido a no sacrificar la naturaleza en aras de un provecho económico inmediato y a privilegiar en cambio el suministro sostenido de alimentos, refugio, energía, agua, medicamentos y otros bienes y servicios que la naturaleza brinda a sus familias. Una mayor apreciación de este enfoque ayudaría a incrementar la tolerancia y la comprensión respecto de las diferencias culturales, siendo esta 
una preocupación fundamental de los movimientos ecofeministas en América Latina.

Es necesario reconocer la interrelación constante entre los ecosistemas y las personas en todo el planeta. La índole de esa interconexión en el sistema socioecológico (Young y otros, 2006; Bono, 2008a) hace que el mero impacto en apenas una parte de dicho sistema afecte al equilibrio global; de allí la importancia de realizar evaluaciones ambientales a escala planetaria y de velar por una mayor equidad distributiva y por la justicia internacional. La grave pobreza que aflige a un tercio de la población del mundo ${ }^{7}$, la feminización de la pobreza ${ }^{8}$ y la transferencia de inequidades entre las mujeres de nacionalidades, condiciones sociales, razas y niveles de educación diferentes a través de la "cadena mundial de cuidados" (Hochschild, 2004) son factores que ponen de manifiesto la necesidad de abordar ese problema. Según Valcárcel (1993), la igualdad debería ser disfrutada por toda la humanidad, pero eso hasta ahora no se ha dado. $\mathrm{Al}$ contrario, nuestras sociedades mantienen marginados a sectores de menores recursos y el resto del planeta permanece insensible al problema. La autora sostiene que sin igualdad no se puede hacer nada para cambiar el orden prevaleciente. De manera similar, Tomás Carpi (2007) afirmó que el desarrollo sostenible debe ser global o no será en absoluto sostenible. En el Informe sobre desarrollo humano se señaló recientemente que los urgentes desafíos mundiales de la sostenibilidad y la equidad se deben abordar en forma conjunta (PNUD, 2011). No se trata aquí de presentar un discurso de tono catastrófico, sino más bien de canalizar nuestra creatividad para combinar el enfoque de ecosistemas con el de género a fin de promover políticas y acciones adecuadas.

\section{Reestructuración de las relaciones de poder}

El Índice de Desigualdad de Género incluido en el Informe sobre Desarrollo Humano (PNUD, 2011) ${ }^{9}$ y el

\footnotetext{
${ }^{7}$ Según estimaciones del Índice de Pobreza Multidimensional, que incluye datos sobre el $79 \%$ de la población mundial, el $31 \%$ de dicha población (1.650 millones de personas) puede calificarse como mutidimensionalmente pobre (PNUD, 2011).

${ }^{8}$ En América Latina, el Índice de Feminización de la Pobreza elaborado por el Observatorio de Igualdad de Género de la CEPAL muestra con claridad que en casi todos los países y zonas (rurales y urbanas) hay más mujeres pobres que hombres pobres, brecha que es especialmente marcada en las mujeres de entre 20 y 59 años de edad en la mayoría de los países.

${ }^{9} \mathrm{Si}$ bien existen críticas a la metodología utilizada por el Programa de las Naciones Unidas para el Desarrollo (PNUD) para calcular el índice de desarrollo relacionado con la mujer y el índice de potenciación de la mujer, ambos anteriores, dichas críticas no niegan la existencia de desigualdades, sino que versan sobre la manera en que se deberían
}

Índice de Equidad de Género elaborado por Social Watch (2012) muestran con claridad que si bien hay grandes variaciones entre países, habitualmente las mujeres trabajan más, ganan menos, constituyen una proporción mayor de analfabetos entre quienes viven en la pobreza absoluta, tienen menos acceso a la educación y menos probabilidades de ocupar posiciones directivas o de participar en instituciones representativas, comen peores alimentos, reciben peores servicios de salud y tienen más probabilidades de sufrir violencia basada en el género o de verse privadas del derecho de nacer, entre otras prácticas injustas (Social Watch, 2011). Según estadísticas sobre la población empleada de 15 o más años de edad elaboradas por el Observatorio de Igualdad de Género de la CEPAL, las mujeres latinoamericanas trabajan entre 8 y 23 horas más por semana que los hombres (trabajo remunerado y no remunerado), y esa brecha oscila entre 22 y 28 horas semanales para la población desocupada. Además, un promedio del $34,7 \%$ de las mujeres carece de ingreso propio, lo que pone de manifiesto su falta de autonomía y su menor participación en el mercado laboral ${ }^{10}$. A pesar de ser las principales dispensadoras de cuidados en el hogar, se las considera "inactivas" para los efectos de las estadísticas laborales tradicionales (Montaño, 2011).

La distribución desigual del poder y los distintos obstáculos a la participación activa de la mujer en los procesos decisorios a nivel del hogar, la comunidad y la sociedad también limita sus posibilidades de ejercer sus derechos y ciudadanía, y guardan directa relación con su falta de protección social y de seguridad (CEPAL, 2004). Como ya se señaló, las feministas esgrimen que las disparidades de género se vinculan con las relaciones de poder jerárquicas, y en ese punto coinciden con algunos ecologistas que llaman la atención sobre el dominio ejercido por los fuertes sobre los débiles, ya se trate de personas o de países. La redefinición de las relaciones de poder resulta tan necesaria para las relaciones en los ámbitos privado y público como para las relaciones personales e internacionales. En ese sentido, el reconocimiento y la valorización del Otro (la mujer o la naturaleza) deberían traducirse en igualdad de tratamiento, de derechos y de oportunidades para desarrollar capacidades respetando los ciclos y los marcos temporales. Hasta ahora las razones éticas y políticas no han sido suficientemente persuasivas como para provocar un cambio ni en el seno de nuestras sociedades ni en el

calcular. Los ajustes sugeridos al respecto podrían traducirse en peores puntuaciones para algunos países (véanse Klasen y Schüler, 2011).

10 Estadísticas del Observatorio de Igualdad de Género de la CEPAL. 
orden mundial, prevaleciendo en cambio los intereses económicos y la resistencia a compartir el poder. Se requieren urgentemente medidas que fomenten la justicia intragénero e intergéneros, así como la igualdad de derechos y oportunidades a fin de llevar la democracia y la equidad a las relaciones personales e internacionales. Ello supondrá una presión a nivel del acceso a los recursos y tecnologías necesarios para avanzar hacia el empoderamiento de la mujer y hacia una concepción inclusiva del desarrollo sostenible, pero si eso no se materializa el efecto negativo sobre las familias, la cohesión social, las políticas de desarrollo, la estabilidad y la seguridad se intensificará y aumentará los riesgos de crisis social, ambiental y económica.

Como ya se indicó, los problemas ambientales plantean grandes desafíos para la gobernanza mundial, debido a los efectos directos e indirectos de las actividades humanas y la interdependencia de los ecosistemas. Por ejemplo, las pérdidas de diversidad biológica afectan al suministro de materias primas en todo el mundo, en tanto que el cambio climático trastorna los ciclos de los ecosistemas, también a escala mundial. Por ende, es esencial actuar simultáneamente a los niveles local y mundial (Bono, 2008b). Hans Bressers y Walter Rosenbaum (2003) recalcaron que, debido a la interdependencia ecológica, la protección ambiental se debe llevar a cabo a distintas escalas y debería estar cubierta por los marcos jurídico e institucional para poder abordar los problemas correctamente. El desafío radica en cómo integrar las distintas escalas geográficas, y también los plazos, instituciones y sectores involucrados en cada nivel. Ello requiere de la colaboración, el diálogo y la acción coordinada entre los actores locales y entre los países, sobre la base de un enfoque no dominante, integrador y cooperativo. Para eso se necesita un nuevo tipo de liderazgo comprometido, que comprenda la mutidimensionalidad de los problemas en toda su amplitud a fin de promover un consenso local y mundial respecto de las políticas públicas que se requieren (Tomás Carpi, 2008).

\section{Cambios en el modelo de desarrollo}

El cuestionamiento del modelo económico prevaleciente es un elemento común de las perspectivas ecológica y feminista. El movimiento ecológico y los grupos de investigación han formulado una serie de propuestas interesantes para un cambio basado en un enfoque sistémico y holístico que pueda responder a las preocupaciones feministas. Un ejemplo al respecto es la obra de Tomás Carpi (2007), citada anteriormente.
En el ámbito de los medios, dentro de su modelo de desarrollo sostenible, este autor señala la innovación tecnológica, la gestión ambiental de los procesos productivos, el cambio institucional, los mecanismos de reglamentación para el sistema económico y la evolución de las relaciones socioculturales y de poder. En cuanto a la finalidad del modelo, el desarrollo sostenible aspira a mejorar la calidad de vida de los seres humanos, así como el desarrollo social, la democracia y la justicia distributiva, preservando al mismo tiempo la capacidad de autorregulación de los ecosistemas naturales para proporcionarnos productos y servicios.

Esa propuesta abarca varias características destacables, algunas de las cuales coinciden con los argumentos ecofeministas, en tanto que otras son más acordes con la perspectiva económica feminista. En primer lugar, salta a la vista que la finalidad del modelo no es la de buscar una acumulación ilimitada, pues coloca a la naturaleza (el pilar ambiental) al mismo nivel que el pilar social. Asimismo, tiene en cuenta la capacidad de carga del planeta para satisfacer las necesidades humanas. A su vez, considera a la salud como una de las relaciones más importantes entre el ser humano y el entorno natural, con lo que presta la debida atención a una importante causa de preocupación tanto para las ecofeministas como para los ecologistas. El modelo incluye la ecoeficiencia, la ecoeficacia y la sostenibilidad en el pilar económico, lo que resalta no solo la percepción de la naturaleza como base fundamental con funciones estratégicas de las que todos dependemos, sino también una perspectiva de largo plazo, esencial para la solidaridad intergeneracional. En vez de buscar un control absoluto sobre la naturaleza, pone el conocimiento al servicio de los límites ecológicos con el objeto de desarrollar su potencial conjunto y separar el desarrollo, por una parte, de la contaminación y la degradación ambiental, por otra. El pilar social incorpora aspectos tales como la calidad de vida (teniendo en cuenta la diversidad de enfoques en función del contexto), la cohesión social, el grado de conciencia, los procesos de aprendizaje y el establecimiento de capacidades. El modelo reconoce que hay que realizar una transformación fundamental a nivel social para lograr el cambio de valores necesario. Por último, el marco institucional (formal e informal) puede promover la adopción de esos nuevos valores al asignar recursos adecuados y fomentar el progreso tecnológico, la gestión de recursos, la educación y el desarrollo de libertades instrumentales, entre muchos otros elementos (Tomás Carpi, 2008).

Este modelo representa sin duda una noción avanzada de sostenibilidad, compatible con la perspectiva 
de género, y demuestra una encomiable receptividad a nuevos valores. En él se hace hincapié en la igualdad, la solidaridad y la cooperación y se llega incluso a proponer que se cambien las relaciones de poder, pese a lo cual habría margen para enriquecerlo aún más integrando la ética del cuidado (la Unión Europea ha reconocido el derecho a recibir cuidados) y reflejando la contribución y el valor del trabajo doméstico y reproductivo, como en la propuesta de Picchio. Por consiguiente, las relaciones dinámicas entre los pilares social y económico debieran reflejar el hecho de que las labores del hogar contribuyen a la actividad económica (tangible e intangible), y el pilar económico debería incluir la equidad de género entre sus principios rectores.
Sobre la base de esas reflexiones, en este trabajo se ha elaborado una visión integradora sobre la sostenibilidad en el sistema socioecológico, que se representa en el gráfico 2.

En el gráfico 2 se muestra un sistema circular y abierto. Las múltiples interacciones dentro y fuera de cada segmento son ilimitadas y podrían registrarse en un sinnúmero de combinaciones y en cualquier orden. En el modelo se reconoce a la naturaleza como la base de todas las actividades del género humano, que proporciona bienes y servicios vitales para satisfacer las necesidades humanas y que a cambio de ello absorbe nuestro impacto. Se trata de una visión que resta importancia al mercado mientras presta atención a la esfera no monetizada de

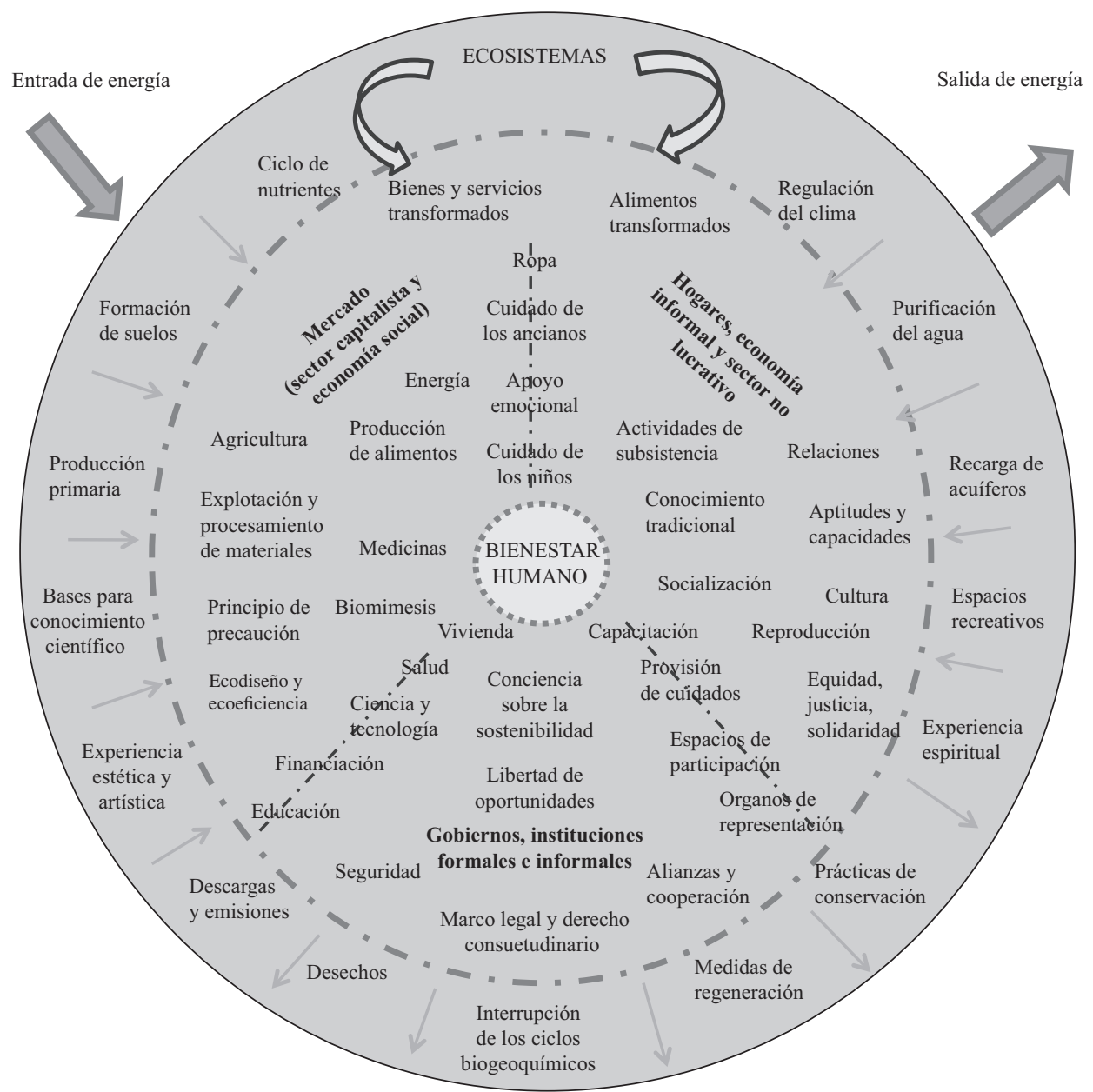

Fuente: elaboración propia. 
la economía. El suministro de cuidados, esencial para los ciclos productivo y reproductivo, se representa no como una tarea que se ha de cumplir, sino como una necesidad que se ha de satisfacer (Bosch, Carrasco y Grau, 2003; Carrasco, 2009).

Esta visión se relaciona con un concepto de bienestar humano que se nutre tanto de los elementos materiales como de los inmateriales, es decir: alimentos, refugio, salud, recursos financieros, pero también apoyo emocional, libertad de elección, participación activa, construcción de capacidades, experiencias espirituales, derecho a suministrar y a recibir cuidados. Todo ello requiere que los componentes del sistema socioecológico funcionen armónicamente, sin sacrificar a ninguno de los proveedores de esos elementos. Las responsabilidades sociales y ambientales de las unidades económicas orientan sus actividades de acuerdo con el principio de precaución y la ecoeficiencia, teniendo siempre en cuenta la capacidad de sustento de la naturaleza. Las instituciones formales e informales adoptan esa noción de un "continuum" multidimensional que forman la naturaleza y el ser humano en espacio y tiempo. De manera contextualizada, ella misma promueve las acciones que se necesitan con el fin de mantener su equilibrio dinámico. Para ello, la tecnología y el conocimiento tradicional nos brindan una mejor comprensión de la naturaleza, armonizando sus ritmos con los nuestros y dotándonos de los medios necesarios para adaptarnos a los cambios.

\section{IV}

\section{Conclusión}

Como se indica en el Informe de la Comisión Mundial sobre el Medio Ambiente y el Desarrollo, titulado "Nuestro futuro común", un mundo en que prevalezcan la pobreza y la desigualdad siempre será proclive a crisis sociales, ecológicas y de otra índole. La ciencia económica no puede seguir haciendo caso omiso de la naturaleza y la población mundial debe poder intervenir en la revisión necesaria del modelo económico. Durán (2011) señala que en su afán por centrarse objetivamente en los bienes y los mercados, la ciencia económica ha olvidado a los seres humanos que producen y consumen, así como a quienes no tienen acceso a los bienes y servicios. Las pautas de producción y consumo prevalecientes no solo comprometen la estabilidad ecológica, sino también la
Los desafíos que se plantean son interdisciplinarios y para afrontarlos se requiere un enfoque no dominante, cooperativo e integrador, así como una sociedad consciente de su impacto individual y colectivo, derivado de lo que ella produce, de cómo lo hace, de qué consume y los efectos de ese consumo. Los ciudadanos han de ser conscientes de sus derechos y responsabilidades. La participación activa y el compromiso de la sociedad en su conjunto resultan esenciales para impulsar y facilitar ese cambio. Una población educada acerca de la sostenibilidad local y global, que fomente la justicia y la equidad tanto dentro de una misma generación como entre distintas generaciones, es un elemento fundamental de ese marco conceptual. Las comunidades y los medios de difusión involucrados activamente en la promoción y defensa de los nuevos valores son fundamentales para superar las inequidades entre los géneros y dentro de estos, cosa que pueden lograr participando eficaz y activamente en el ámbito público mediante diálogos, alianzas y oportunidades para presentar sus ideas y propuestas. Otra prioridad es la de un nuevo liderazgo, que debe ser verdaderamente democrático, estar a tono con las necesidades de la sociedad actual y poseer una comprensión integral de la manera en que funcionan los sistemas socioecológicos y de su capacidad de resiliencia. Un liderazgo de esa índole es vital para que las políticas se diseñen y ejecuten desde una perspectiva holística, de tal modo que no se tengan que reajustar con posterioridad para incluir medidas limitadas con relación a la sostenibilidad.

equidad y la justicia mundiales, pues entrañan riesgos para las vidas humanas, su bienestar actual y el de sus descendientes. Al mismo tiempo, las persistentes desigualdades de género y la feminización de la pobreza hacen necesario reevaluar, en términos éticos y económicos, la contribución de la mujer a la sociedad y su derecho a las mismas oportunidades, a fin de que la igualdad universal se vuelva realidad. Para alcanzar el desarrollo sostenible todos deben poder disfrutar de los mismos espacios, decidir de qué manera usar su propio tiempo, acceder a recursos y representarse a sí mismos en los órganos políticos y sociales. El concepto que se necesita en este sentido, pero que todavía sigue en elaboración, es el de un Estado activo en tanto garante de 
derechos (Montaño, 2010). Pero nada de eso será posible si se trastornan irreversiblemente las características que posibilitan la vida sobre la Tierra. Así, se insta a los proponentes del ecologismo y el feminismo a colocarse por sobre sus desacuerdos y explorar las sinergias que puedan ayudar a impulsar la necesaria transformación del modelo prevaleciente. No existe una fórmula única, sencilla o definitiva para lograrlo, pero hay margen para el debate, continuar con la investigación y la acción política tendientes a provocar los cambios que nuestra sociedad necesita de manera urgente.

Se debería optar por una solución sistémica y una visión integradora sobre la sostenibilidad. La reformulación del ciclo económico propuesta por Picchio, para incluir el trabajo doméstico y reproductivo no remunerado, se vería reforzada si se le agregara la perspectiva ecológica. Su modelo se podría colocar dentro del marco de la naturaleza para reflejar los intercambios entre el ser humano y el ecosistema, y ampliar la dimensión temporal, abordando con ello las preocupaciones de las feministas y de los ecologistas por igual. Pero las reformas teóricas no son suficientes para promover las transformaciones necesarias, sino que deben ir acompañadas de políticas públicas adecuadas y de cambios en los valores fundamentales, como lo plantean ambos movimientos. Hay pruebas empíricas de avances en la igualdad jurídica en determinados contextos, pero queda mucho por hacer para ampliar su alcance y transformarlos en cambios de comportamiento efectivos y sistemáticos a escala mundial. Se necesita una alianza robusta para fomentar valores adecuados. Reestructurar las relaciones de poder a los niveles privado y público es otra tarea imprescindible para poder superar las inequidades insustentables (asentadas no solo en las diferencias intergénero, sino también en las que se registran intragénero). Para eso es esencial que el conjunto de la sociedad se involucre, de modo que esa participación pase de ser un derecho a convertirse en una herramienta eficaz que promueva un consenso acerca de cómo cambiar el modelo de desarrollo. Al respecto, la definición de desarrollo sostenible dada por Tomás Carpi representa un buen punto de partida, que se podría fortalecer si abordara el tema de la prestación de cuidados y las consideraciones de las economistas feministas.

Habiendo explorado las sinergias potenciales, en este estudio se ha presentado una visión integradora sobre la sostenibilidad que representa la multidimensionalidad fluida de la vida en el sistema socioecológico. Asimismo, se han resaltado las interconexiones fundamentales que existen entre la humanidad y la naturaleza, entre las esferas privada y pública, así como entre la economía de mercado y los hogares. Para ese enfoque holístico se necesitan nuevos valores, relaciones de cooperación y una comprensión no dualista de la vida. Al mismo tiempo, se considera que las necesidades emocionales y materiales revisten igual importancia para el bienestar, y el modelo debe respetar la capacidad de resiliencia de la naturaleza y el ser humano.

Teniendo en cuenta que los desafíos que enfrenta la humanidad en este momento particular de crisis requieren no solo propuestas, sino también una acción política para promover la transformación necesaria, resulta esencial un liderazgo profundamente comprometido con esos desafíos. Es posible alcanzar una sostenibilidad integradora, enraizada en una sociedad que tenga plena conciencia de sus derechos y responsabilidades, pero para ello será necesaria una decisiva acción colectiva.

\section{Bibliografía}

Agarwal, Bina (1992), "The gender and environment debate: lessons from India”, Feminist Studies, vol. 18, $\mathrm{N}^{\circ}$ 1, College Park, Maryland, Feminist Studies Inc.

Agra Romero, María Xosé (comp.) (1998), Ecología y feminismo, Granada, Comares.

Almenar Asensio, Ricardo (2008), "Indicadores de sostenibilidad", Estrategias y elementos para un desarrollo sostenible, Emérito Bono y Juan A. Tomás Carpi (eds.), vol. III-III, Valencia, Nau Llibres.

Asamblea General de las Naciones Unidas (2003), Resolución aprobada por la Asamblea General. Decenio de las Naciones Unidas de la Educación para el Desarrollo Sostenible (A/ RES/57/254) [en línea] http://www.un.org/ga/search/view_doc. asp?symbol=A/RES/57/254\&referer=http://www.un.org/depts/ dhl/resguide/r57.htm\&Lang=S.

(1987), Informe de la Comisión Mundial sobre el Medio Ambiente y el Desarrollo (A/42/427) [en línea] http:// www.un.org.
Biehl, Janet (1991), Rethinking Ecofeminist Politics, Boston, South End Press.

Bono Martínez, Emérit (2008a), "Cambio climático y sustentabilidad económica y social. Implicaciones sobre el bienestar social", CIRIEC-España, Revista de Economía Pública Social y Cooperativa, $\mathrm{N}^{\circ} 61$, Valencia, Centro Internacional de Investigación e Información sobre la Economía Pública, Social y Cooperativa (CIRIEC).

(2008b), "Retos de la política medioambiental: Un enfoque global", Desafíos actuales de la política económica: Un enfoque estructural y social, J. Jordán Galduf y A. Sánchez (coords.), Navarra, Aranzadi.

Bosch, Anna, Cristina Carrasco y Elena Grau (2003), "Verde que te quiero violeta: Encuentros y desencuentros entre feminismo y ecologismo", La historia cuenta. Del crecimiento económico al desarrollo humano sostenible, Enric Tello, España, El Viejo Topo. 
Bosselmann, Klaus (2004), "In search of global law: the significance of the Earth Charter", Worldviews: Global Religions, Culture, and Ecology, vol. 8, $\mathrm{N}^{\circ}$ 1, Brill.

Bressers, Hans y Walter Rosenbaum (eds.) (2003), Achieving Sustainable Development: The Challenge of Governance across Social Scales, Nueva York, Praeger Publishers.

Carrasco, Cristina (2009), "Mujeres, sostenibilidad y deuda social", Revista de Educación, número especial.

Carrasco, Cristina y Maribel Mayordomo (2000), "Los modelos y estadísticas de empleo como construcción social: La encuesta de población activa y el sesgo de género", Política y Sociedad, vol. 34, Madrid, Universidad Complutense de Madrid.

Carrasco, Cristina y Mónica Serrano (2011), "Lights and shadows of household satellite accounts: the case of Catalonia, Spain", Feminist Economic, vol. 17, $\mathrm{N}^{\circ}$ 2, Taylor \& Francis.

Carson, Rachel (1962), Silent Spring, Nueva York.

CEPAL (Comisión Económica para América Latina y el Caribe) (2012), La sostenibilidad del desarrollo a 20 años de la Cumbre de la Tierra. Avances, brechas y lineamientos estratégicos para América Latina y el Caribe (LC/L.3346/ Rev.1), Santiago de Chile.

(2004), Caminos hacia la equidad de género en América Latina y el Caribe (LC/L.2114(CRM.9/3)), Santiago de Chile.

Conferencia de las Naciones Unidas sobre el Desarrollo Sostenible (2012), "The future we want" [en línea] http://www.uncsd2012. org/thefuturewewant.html.

Costanza, Robert (2003), "Ecological economics is post-autistic", Post-autistic Economics Review vol. 20, № 3 [en línea] http:// www.paecon.net/PAEReview/issue20/Costanza20.htm.

(1994), "Three general policies to achieve sustainability", Investing in Natural Capital: The Ecological Economics Approach to Sustainability, AnnMari Jansson y otros (eds.), Washington, D.C., Island Press.

DAES (Departamento de Asuntos Económicos y Sociales) (2009), Policy Brief, $\mathrm{N}^{\circ} 20$, Naciones Unidas [en línea] http://www. un.org/en/development/desa/policy/publications/policy_briefs/ policybrief20.pdf.

Daly, Herman (2005), "Economics in a full world", Scientific American, vol. 293, $\mathrm{N}^{\circ} 3$, Scientific American, Inc. septiembre.

(1996), Beyond Growth. The Economics of Sustainable Development, Massachusetts, Beacon Press.

D’Eaubonne, Françoise (1974), Le feminisme ou la mort, París, P. Horay.

De Beauvoir, Simone (1968), El segundo sexo, Buenos Aires, Siglo Veinte.

Del Saz, Salvador (2008), "Valoración económica de los bienes ambientales", Técnicas e instrumentos de gestión ambiental, vol. IV, Emérito Bono y Juan Antonio Tomás Carpi, Valencia, Nau Llibres.

Durán, María Ángeles (2012), El trabajo no remunerado en la economía global, Madrid, Fundación BBVA.

(2011), "El trabajo del cuidado en el marco macroeconómico", El trabajo del cuidado en América Latina y España, Documento de Trabajo, $\mathrm{N}^{\circ} 54$, Madrid, Fundación Carolina-CeALCI.

(2001), "El análisis de exhaustividad en la economía española", Tiempos, trabajos y género, Cristina Carrasco (ed.), Barcelona, Publicacions Universitat.

Durán, María Angeles y Vivian Milosavljevic (2012), "Unpaid work, time use surveys and care demand forecasting in Latin America", Documento de Trabajo, $\mathrm{N}^{\circ}$ 7, Madrid, Fundación BBVA.

Freedman, Jane (2004), Feminismo ¿Unidad o conflicto?, Madrid, Narcea S.A.

Grossman, Britt (1999), "Pollution tax", Encyclopedia of Law and Economics [en línea] http://murallivre.net/Archives/2500book. pdf.

Heller, Chaia (1999), Ecology of Everyday Life: Rethinking the Desire of Nature, Montreal, Black Rose Books.
Howie, Gillian y Ashley Tauchert (2002), "Feminist dissonance: the logic of late feminism", Third Wave Feminism, Stacy Gillis, Gillian Howie y Rebecca Munford (eds.), Basingstoke, Palgrave.

Humphrey, Mathew (ed.) (2001), Political Theory and the Environment. A Reassessment, Londres, Frank Cass Publishers.

Hochschild, Arlie 2004, "Las cadenas mundiales de afecto y asistencia”, En el límite: la vida en el capitalismo global, Anthoony Giddens, Will Hutton (eds.), Barcelona, Tusquets.

Jolly, Susie (2004), "Gender myths", BRIDGE [en línea] http://www. bridge.ids.ac.uk/go/home\&id=52913\&type=Document.

Kao, Grace (2010), "The universal versus the particular in ecofeminist ethics", Journal of Religious Ethics, vol. 38, No 4, Wiley.

Klasen, Stephan y Dana Schüler (2011), "Reforming the genderrelated development index and the gender empowerment measure: implementing some specific proposals", Feminist Economics, vol. 17, $\mathrm{N}^{\circ} 1$, Taylor \& Francis.

Kriström, B. (1995), "Theory and applications of the contingent valuation method", documento presentado en el curso "Economía ambiental: Valoración, recursos naturales y política económica", Barcelona, Universidad Internacional Menéndez y Pelayo, junio.

Martínez Alier, Joan (2007), "El ecologismo popular", Ecosistemas, vol. 16, $\mathrm{N}^{\circ} 3$, Madrid, Asociación Española de Ecología Terrestre.

Meadows, Donella y otros (1972), The Limits to Growth, Nueva York, Universe Books.

Mellor, Mary (1997), Feminism and Ecology, Cambridge, Polity Press.

Merchant, Carolyn (1995), Earth Care: Women and the Environment, Nueva York, Routledge.

Mies, María y Vandana Shiva (1997), Ecofeminismo. Teoría, crítica y perspectiva, Barcelona, Icaria.

Montaño Virreira, Sonia (2011), "Las políticas de cuidado en América Latina", El trabajo del cuidado en América Latina y España, Documento de Trabajo, $\mathrm{N}^{\circ}$ 54, Madrid, Fundación Carolina -CeALCI.

(2010), "El cuidado en acción", El cuidado en acción. Entre el derecho y el trabajo, serie Cuadernos de la CEPAL, $\mathrm{N}^{\circ}$ 94 (LC/G.2454-P), Sonia Montaño Virreira y Coral Calderón Magaña (coords.), Santiago de Chile, Comisión Económica para América Latina y el Caribe (CEPAL). Publicación de las Naciones Unidas, $\mathrm{N}^{\circ}$ de venta: S.10.II.G.35.

Moore, Niamh (2004), "Ecofeminism as a third wave feminism? Essentialism, activism and the Academy", Third Wave feminism, Stacy Gillis, Gillian Howie y Rebecca Munford (eds.), Nueva York, Palgrave MacMillan.

Naredo, José Manuel (2006), Raíces económicas del deterioro ecológico y social. Más allá de los dogmas, Madrid, Siglo XXI.

Nash, Roderick Frizier (1989), The Rights of Nature: A History of Environmental Ethics, Wisconsin, The University of Wisconsin Press.

North, Douglas (1990), Instituciones, cambio institucional y desempeño económico, México, D.F., Fondo de Cultura Económica.

Novo, María (coord.) (2007), Mujer y medio ambiente. Los caminos de la visibilidad: Utopías, educación y nиevo paradigma, Madrid, Los libros de la Catarata.

Observatorio de Igualdad de Género para América Latina y el Caribe/ Comisión Económica para América Latina y el Caribe (CEPAL) (2010), "Indicadores de género", Santiago de Chile.

Picchio, Antonella (2005), "La economía política y la investigación sobre las condiciones de vida", Por una economía sobre la vida, Gemma Cairó i Céspedes y Maribel Mayordomo (comps.), Barcelona, Icaria-Más Madera.

(2001), "Un enfoque macroeconómico ampliado de las condiciones de vida", Tiempos, trabajos y género, Cristina Carrasco (ed.), Barcelona, Publicacions Universitat. 
Pigou, Arthur Cecil (1946), La economía del bienestar, Madrid, M. Aguilar Editor. Publicado originalmente en 1920.

Pla Julián, Isabel (2009), "La feminización de las migraciones y la cadena global de cuidados" [en línea] http://www.agenciasinc. es/Opinion/La-feminizacion-de-las-migraciones-y-la-cadenaglobal-de-cuidados.

(coord.) (2008), "Luces y sombras del recurso al empleo de hogar", Quaderns Feministes, № 8, Valencia, Universidad de Valencia.

Plumwood, Val (2002), Environmental Culture: The Ecological Crisis of Reason, Nueva York, Routledge.

(1993), Feminism and the Mastery of Nature, Londres, Routledge.

(1991), "Nature, self, and gender: feminism, environmental philosophy, and the critique of rationalism", Hypatia, vol. 6, $\mathrm{N}^{\circ}$ 1, Ecological Feminism.

PNUD (Programa de las Naciones Unidas sobre el Desarrollo) (2011), Informe sobre desarrollo humano 2011. Sostenibilidad y equidad: Un mejor futuro para todos [en línea] http://hdr.undp. org/es/informes/mundial/idh2011/descargar/.

PNUMA (Programa de las Naciones Unidas sobre el Medio Ambiente) (coord.) (2005), The Millenium Ecosystems Assessment [en línea] http://www.millenniumassessment.org.

Puleo, Alicia (2008), "Libertad, igualdad, sostenibilidad. Por un ecofeminismo ilustrado", Isegoría. Revista de Filosofía Moral y Política, $\mathrm{N}^{\circ} 38$, Madrid, Instituto de Filosofía, enero-junio. (2007), “QQue é o ecofeminismo?”, Andaina: Revista do Movemento Feminista Galego, $\mathrm{N}^{\circ}$ 47, Asociación Galega da Muller Pan e Rosas.

(2002), "Feminismo y ecología: Un repaso a las diferentes corrientes de ecofeminismo", El Ecologista, № 31, Madrid, Ecologistas en Acción.

Redclift, Michael (2009), "Sustainable development (1987-2005) - an oxymoron comes of age", Problems of Sustainable Development, vol. 4, N 1 [en línea] http://ssrn.com/abstract=1481709.

Ress, Mary Judith (2003), "Reflexiones sobre el ecofeminismo en América Latina”, Religión y género, Sylvia Marcos (ed.), Madrid, Trotta.

Rivera, María Milagros (1991), "La historia de las mujeres y la conciencia feminista en Europa", Mujeres y sociedad: Nuevos enfoques teóricos y metodológicos, Lola Luna (ed.), Barcelona, Universidad de Barcelona.

Rocheleau, Dianne, Barbara Thomas-Slayter y Esther Wangari (eds.) (1996), Feminist Political Ecology: Global Issues and Local Experiences, Nueva York, Routledge.

Rodríguez Enríquez, Corina (2012), "La cuestión del cuidado: ¿El eslabón perdido del análisis económico?", Revista de la CEPAL, $\mathrm{N}^{\circ} 106$ (LC/G.2518-P), Santiago de Chile, abril.

Salleh, Ariel (1997), Ecofeminism as Politics: Nature, Marx and the Postmodern, Londres, Zed Books.

(1992), "The ecofeminism/deep ecology debate: a reply to patriarchal reason", Environmental Ethics, vol. 14, $\mathrm{N}^{\circ} 3$, Charlottesville, Philosophy Documentation Center.
Sánchez, Cristina (2001), "Genealogía de la vindicación", Feminismos. Debates teóricos contemporáneos, Elena Beltrán y otros, Madrid, Alianza Editorial.

Schmid, Alfred Allan (1987), Property, Power and Public Choice. An Inquiry into Law and Economics, Nueva York, Praeger.

Sessions, Robert (1991), "Deep ecology versus ecofeminism: healthy differences or incompatible philosophies?", Ecological Feminism, vol. 6, $\mathrm{N}^{\circ}$ 1, Hypatia.

Social Watch (2012), "El índice de equidad de género 2012" [en línea] http://www.socialwatch.org/es/node/14380.

(2011), "What is sustainable development? The evolution of the idea" [en línea] http://www.socialwatch.org/sites/ default/files/report2011_sustainableDevelopment_0.pdf.

Stoddart, Mark C.J. y David B. Tindall (2011), "Ecofeminism, hegemonic masculinity and environmental movement participation in British Columbia, Canada, 1998-2007: "Women always clean up the mess"', Sociological Spectrum, vol. 31, $\mathrm{N}^{\circ}$ 3, Taylor \& Francis.

Tomás Carpi, Juan Antonio (2008), "El desarrollo local sostenible en clave estratégica", CIRIEC-España. Revista de Economía Pública Social y Cooperativa, $\mathrm{N}^{\circ}$ 61, Valencia, Centro Internacional de Investigación e Información sobre la Economía Pública, Social y Cooperativa (CIRIEC), agosto.

(2007), "Desarrollo sostenible", Estrategias y elementos para un desarrollo sostenible, vol. I-III, Emérito Bono y Juan Antonio Tomás Carpi (dirs.), Valencia, Nau Llibres.

UNESCO (Organización de las Naciones Unidas para la Educación, la Ciencia y la Cultura) (2009), "Declaración de Bonn" [en línea] http://www.esd-world-conference-2009.org/fileadmin/ download/ESD2009_BonnDeclarationESP.pdf.

Valcárcel, Amelia (2008), Feminismo en el mundo global, Madrid, Cátedra.

(1993), Del miedo a la igualdad, Barcelona, Crítica.

Vig, Norman y Regina Axelrod (eds.) (1999), The Global Environment: Institutions, Law and Policy, Londres, Earthscan.

Walker, Brian y otros (2004), "Resilience, adaptability and transformability in social-ecological systems", Ecology and Society, vol. 9, $\mathrm{N}^{\circ} 2$ [en línea] http://www.ecologyandsociety. org/vol9/iss2/art5.

Warren, Karen J. (2009), "Le pouvoir et la promesse de l'écofeminisme", Multitudes, vol. 1, $\mathrm{N}^{\circ} 36$.

Warren, Karen J. y Jim Cheney (1991), "Ecological feminism and ecosystem ecology", Ecological Feminism, vol. 6, $\mathrm{N}^{\circ}$ 1, Hypatia Inc.

Young, Oran y otros (2006), "The globalization of socioecological systems: an agenda for scientific research", Global Environmental Change, vol. 16, $\mathrm{N}^{\circ} 3$, Amsterdam, Elsevier.

Zimmerman, Michael E. (1987), "Feminism, deep ecology and environmental ethics", Environmental Ethics, vol. 9, $\mathrm{N}^{\circ} 1$, Charlottesville, Philosophy Documentation Center. 